\title{
WAYS OF EFFICIENCY IMPROVEMENT OF THE ORGANIZATION OF STUDENTS' INDEPENDENT WORK WITH COMPUTER TECHNOLOGIES USAGE
}

\author{
Inna Plotnikova ${ }^{1,}{ }^{*}$, Oksana Efremova $^{1}$, Nataliya Chicherina $^{1}$, Victor Dalinger $^{2}$ \\ ${ }^{1}$ Tomsk Polytechnic University, Institute of Non-Destructive Testing, 634050, Tomsk, Russia \\ ${ }^{2}$ Omsk State Pedagogical University, 644099, Omsk, Russia
}

\begin{abstract}
Recently the need for the qualified engineering personnel increases in the world. High-quality preparation of such shots begins at the university already with the first courses and it is directly connected with the effective organization of students' independent work. In the article the organization of independent work when training students of technical colleges in mathematics with use of computer means is considered. The complex of the tasks developed by teachers included tasks in mathematics of four levels. It is shown that the independent solution of problems of different levels by the students of experimental group contributed to the development of mathematical abilities.
\end{abstract}

\section{Introduction}

At the design of working programs of subjects, courses, disciplines (modules) in higher education institution the appropriate educational technologies which allow to provide in the most effective way the achievement of the planned results of training are provided.

The intensification of educational process and new requirements to it force teachers to find new ways of increase of independent work efficiency. In this regard, the role of students 'independent work considerably raises. At the same time it is possible to use new forms of the organization and control of students 'independent work, or to improve already available traditional ones. Processes of a computerization and informatization inevitably influence both knowledge forms, and training technologies.

In the modern conditions the functions of stimulation of students'cognitive activity, optimization of their independent work, ensuring availability, maximum presentation and timely updating of a training material are the functions of electronic training.

Various elements of electronic training have strongly entered the educational process of higher educational institutions. However, the question of efficiency of use of electronic training in educational process remains open nowadays.

\footnotetext{
${ }^{*}$ Corresponding author: inna@tpu.ru
} 
In the academic circles the question of efficiency of use of electronic training in development of abilities of students in the course of educational activity, in particular mathematical abilities of students is constantly discussed. Importance of this problem is caused by the fact that it is aware of mathematics there is a mastering not only knowledge necessary in professional activity of future expert, but also development of abilities to the analysis and synthesis which are the key to successful work in any field of activity.

Thus, the problem of creation and use of new information technologies in training (and especially in training in mathematics) becomes more and more relevant.

We will notice that use of computer technologies is not end in itself, but means of increase in efficiency of educational process and is focused on its information support.

Nowadays many higher educational institutions develop tools, including the automated training systems, for drawing up individual trajectories of training and assessment of real academic loading.

Computer technologies are used at schools and in higher education institutions in different contexts [1]. A part of researchers use computers for modeling and visualization of objects [2-5], during the work on creative projects [6]. It is necessary when training in mathematics, physics, biology and other disciplines [7].

Other researchers consider influence of the computer on pupils' behavior when training them by means of game technologies [8,9], for estimation of knowledge [10-13], as an assistant for development of discipline on remote access, for exchange of knowledge on social networks $[14,15]$, when training mentally retarded pupils, students with the low level of knowledge [16,17], etc.

We want to apply computer technologies not only as the technologies that help to estimate adequately knowledge of a subject, but also contribute to the development in the studying abilities in the process of educational activity.

\section{Methodology}

Authors offer a complex of tasks for the organization of both classroom, and out-of-class independent work of students at the course of mathematics. The peculiarity of the developed complex is the use of the computer as a mediator between the teacher and the student, assistance in the organization of independent work of students at the individual level, implementation of regular monitoring with the subsequent correction of the training process, orientation to a motivational component of educational process.

The organization of independent work offered by authors was carried out with use of the training system which has been developed by teachers of the Tomsk Polytechnic University.

We will consider the organization of students' independent work on the example of a mathematics course.

At the initial stage there took place identification of the student (the choice of group of the list and a surname of the student in the database). After the online registration the student chose a subject and got acquainted with the methodical instructions on a subject.

Further the student passed to studying of the theory, and then started fulfilling the tasks. The student had an opportunity to change a training trajectory, pass the theory, at once to start performance of tasks. For each correct answer to the student a certain number of points according to the rating system of assessment was charged. The result depended on the level of a task complexity.

The tasks are presented by four levels. Tasks of the first level have been formulated in the form of theoretical questions or presented in the form of drawings with the choice of answers from the offered variants. Problems which students usually solve at the classroom lessons are considered as the tasks of the second level. Such tasks belong to standard tasks. Their decision 
allows to learn the basic concepts and properties characterizing concepts. At difficulty in the decision there is an opportunity to use "Hint" which arrives in the form of a floating window. At the same time the student sees the number of points which is removed for a task when using "Hint" on the computer screen. The student can address the theory or the reference book for what points aren't removed as well.

The third level is presented by algorithmic tasks, but at their decision there is no opportunity to address "Hint". The answer is entered in the form of the numerical answer into the specially allotted field, or the sequence of the decision is restored, or are chosen compliance between objects.

For the answer to the task connected with sequence restoration, the student at first chose the first, on his opinion, the element in the sequence and established an order of its following, further to the second, etc.

Change of an order and viewing of the received sequence can be carried out before final input of the answer.

The example of a task for compliance is presented in Figure 1.

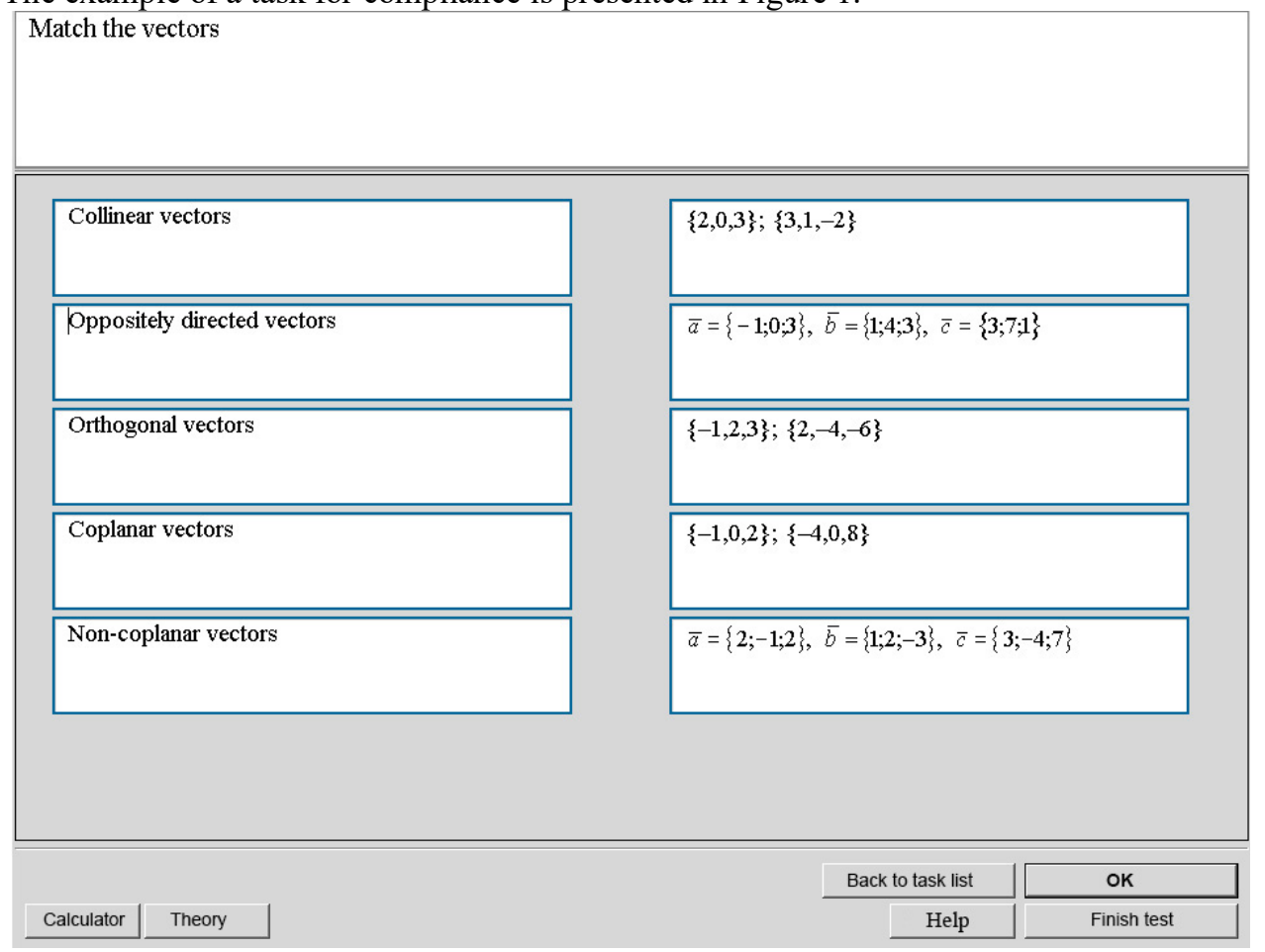

Fig.1. «Matching» task.

Tasks of the fourth level are presented by tasks at which solution the application of mathematics in practical activities is shown. The targets of the fourth level are the generally physical tasks interesting to students of technical university.

The example of a task of the fourth level is given below.

The statement of the task. From the hole having the form of the truncated cone with a big radius of $R_{l}$ and smaller radius of $R_{2}$ it is necessary to take out some mix having the changeable density of $p(x)=a x+p_{0}$. Here $\mathrm{x}$ is the coordinate (depth) concerning the earth level. It changes ranging from 0 to $\mathrm{N}$.

It is required not only to find the spent work, but also to answer some questions. 
For example. Whether it will be better to make a hole of the same volume, but in the form of the cylinder? How will work change if before taking out to mix this mixture so that its density became uniform?

The main condition is that the fourth level task has to be not from the textbook. It means that information on an object isn't necessary and sufficient for the decision (it is possible that it is absent and it is necessary to find), and it means that there is no ready answer to which it is possible to compare the result. And still it means that there is no ready template on which it is possible to solve. Therefore, the student has to show knowledge of the substantial side and existence of theoretical thinking.

Having performed a task of the fourth level, the student loads the scanned decision for check by his teacher.

After finishing the subject of a course the student passes the current control work.

\section{Research results and discussion}

For both groups supported identical conditions: the research was conducted in the first half of the day (11:00) in audience, duration of a research was 30 minutes investigated students carried out testing independently; the use of electronic devices was forbidden.

Comparison of the testing results separately on each task offered examinees has shown that students after training in mathematics in an experimental technique coped with tasks of the checking test of the level of synthetic and analytical skills development much more surely.

After training in mathematics in the majority of questions (in 14 of 20 tasks that makes $70 \%$ of questions) abilities of experimental group students to the analysis and synthesis were much higher, than at the students of the control group.

In five of twenty offered tasks (it has made $25 \%$ of questions) more than $80 \%$ of experimental group students have shown excellent results in comparison with an indicator of control group students. At the end of the experiment in two of twenty questions (it has made $10 \%$ of number of tasks) $90 \%$ of experimental group students have shown high level of development of abilities to the analysis and synthesis. For the comparison: the number of tasks in which $90 \%$ control group students have succeeded was only $5 \%$.

In six of twenty tasks ( $30 \%$ of questions) the number of the experimental group students who have answered right has exceeded twice number of the students who have shown the correct answers to test questions prior to the experiment.

And the number of tasks which less than a half of the interviewed students have answered right has made at the first year $60 \%$ (twelve of twenty offered tasks). In $25 \%$ of tasks (five of twenty questions) the difference between the number of the examinees who have successfully coped with a task before electronic training made from $21 \%$ to $45 \%$.

And only in three of twenty tasks (15\% of questions) experimental group students after training of a mathematics course couldn't surpass the results of control group students.

Comparison of testing results to results of the academic progress of experimental group students showed that the high level of analytical and synthetic skills development allows the student to learn a training material more effectively.

All above is the evidence of efficiency of use of e-learning in mathematics in aspect of development of mathematical abilities to the analysis and synthesis.

\section{Conclusions}

Certainly, the introduction of mathematical tasks into the educational process depends on the level of students' mathematical competence (understanding as an opportunity to solve 
professional problems by mathematical methods). Therefore at an initial stage the tasks of the first, second and third levels aim at the development of mathematical abilities to the analysis and synthesis of the studied material.

The statement of educational targets of the fourth level (applied tasks) demands quite serious work of the teacher.

These tasks have to possess the whole set of characteristics:

1) in the perspective they have to be clear to students;

2) at their decision students have to illustrate the studied material and tools for the purpose of his fixing;

3) they have to be relevant.

Use of applied tasks in mathematics leads to increase in motivation of students on training, to creation of communications between the theory and practice and also updatings of students knowledge from other areas and disciplines and to the working off the skills of information search.

In the conclusion we will note that use of computer technologies in the educational process of a higher educational institution is justified and extremely expedient, and a variety of forms and methods of the independent work organization allows to make active the creative potential of students.

\section{References}

[1] M. Hadfield, M. Jopling, Innovations in Education and Teaching International 51(6), 607(2014) doi:10.1080/14703297.2014.924747

[2] B.R.J Jansen, E. De Lange, M.J. Van der Molen, Research in Developmental Disabilities 34 (5), 1813 (2013) doi: 10.1016/j.ridd.2013.02.022

[3] M. Planchard, EDG J 71(2), 1 (2007)

[4] V.S. Sherstnyov, A.I. Sherstnyova, I.A. Botygin, D.A. Kustov, Key Engineering Materials 685, 867 (2016) doi: 10.4028/www.scientific.net/KEM.685.867

[5] S. Obuhov, I. Plotnikov, M. Surkov, L.Sumarokova, K. Savkin, MATEC Web of Conferences 91, 01036 (2017) doi:10.1051/matecconf/20179101036

[6] O. N. Efremova, I.V. Plotnikova, O.N. Tchaykovskaya, J Ponte 73(4), 158 (2017) doi: 10.21506/j.ponte.2017.4.45

[7] N. V. Chicherina, V. Kazakov, O. Yu. Korneva, E. A. Titenko, The European Proceedings of Social \& Behavioural Sciences (EpSBS) 19, 349 (2017) doi:10.15405/epsbs.2017.01.47

[8] D. Martinov, G.H. Burgess, C.M. Pomerleau, C. Marin, Computers in Human Behavior 49, 487 (2015) doi: 10.1016/j.chb.2015.03.039

[9] N. V. Chicherina, V. A. Tolkacheva, European Proceedings of Social \& Behavioural Sciences (EpSBS) 19, 683 (2017) doi:10.15405/epsbs.2017.01.90

[10] C. Timmers, B. Veldkamp Computers and Education 56(3), 923 (2011) doi: 10.1016/j.compedu.2010.11.007

[11] C. Timmers, J. Braber-Van Den Broek, S. Van Den Berg Computers and Education 60(1), 25 (2013) doi: 10.1016/j.compedu.2012.07.007

[12] C. F. Timmers, A. Walraven, B. P. Veldkamp, Computers and Education 87, 1 (2015) doi: 10.1016/j.compedu.2015.03.012

[13] F.M. Van Der Kleij, T.J.H.M. Eggen, C.F. Timmers, B.P. Veldkamp, Computers and Education 58(1), 263 (2012) doi: 10.1016/j.compedu.2011.07.020

[14] N. Behringer, K. Sassenberg, Computers in Human Behavior 48, 290 (2015) doi: $10.1016 /$ j.chb.2015.01.069 
[15] A.E. Goldshtein, G.V. Vavilova, S.V. Mazikov, MATEC Web of Conferences 79, 01009 (2016) doi:10.1051/matecconf/20167901009

[16] F. Lai, R. Luo, L. Zhang, X. Huang, S. Rozelle, Economics of Education Review 47, 34 (2015) doi: 10.1016/j.econedurev.2015.03.00

[17] V.V. Redko, N.S. Starikova, L.A. Redko, G.V. Vavilova, IOP Conference Series: Materials Science and Engineering 81, 012083 (2015) doi: 10.1088/1757$899 X / 81 / 1 / 012083$ 